
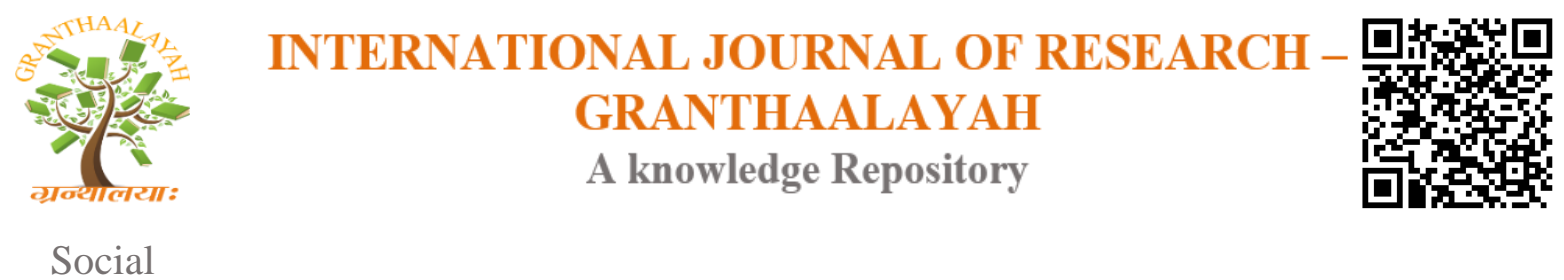

\title{
ROLE OF GRAPHIC DESIGN FOR THE INNOVATION PROCESS OF AN EDUCATION PROJECT
}

\author{
Marco Aurélio Sanfins ${ }^{1}$, Morgana Jesus Masuko ${ }^{2}$, Pablo Silva Machado Bispo dos Santos \\ ${ }^{3}$, Paula dos Santos Figueiredo ${ }^{4}$ \\ 1, 2, 3,4 Núcleo de Estudos Empresariais e Sociais - NEES, Universidade Federal Fluminense - \\ UFF, Brasil
}

\begin{abstract}
Increasingly, society is faced with the need to acquire a great deal of educational and cultural information, which is constantly produced by science in a short time. This fact makes more and more the teaching system to walk in search of innovating its tools that, in an objective way and with the desired efficiency, aim to supply this demand. This article illustrates the importance of graphic design in the production of various support materials that help in the generation of content for the different courses that are offered and make up the core portfolio of transdisciplinary studies of the present university. The importance of the role of the graphic designer in the organizational structure of the nucleus has been shown to be of high relevance, including gaining a prominent role in making decisions about the process of creating a given course.
\end{abstract}

Keywords: Graphic Design; Visual Communication; Teaching Project; Nucleus of Studies; Teaching Innovation; Design and Education.

Cite This Article: Marco Aurélio Sanfins, Morgana Jesus Masuko, Pablo Silva Machado Bispo dos Santos, and Paula dos Santos Figueiredo. (2019). "ROLE OF GRAPHIC DESIGN FOR THE INNOVATION PROCESS OF AN EDUCATION PROJECT." International Journal of Research - Granthaalayah, 7(2), 134-143. 10.29121/granthaalayah.v7.i2.2019.1015.

\section{Introduction}

The design professional has many productive possibilities in various means of application. The activities of the designer in education are sometimes associated with the introduction of new technologies in the pedagogical context or the development of objects and didactic materials that can be used in the classroom [1], but should not be limited to this. Considering design as the attribution of characteristics to an object in order to allow a certain interaction of the user with the world through it, it is plausible to say that design can change the way we face the world. In this sense, we understand that design is the activity that enables us to develop new forms of mediation between subjectivity and objectivity, the realization of what Paulo Freire [2] called "world reading, that is, giving meaning to elements of the concreteness of the real which in other circumstances would not have relevant meaning for the subject with which these elements present themselves." 
In visual language the graphic designer uses his knowledge to organize the elements of a composition so that the transmission of information is simple and effective. The ease with which the user communicates with an object influences how the relationship occurs, the durability, and the pleasure of the exchange. When it comes to education it is of the utmost importance that the student has an interest in acquiring and keeping gaining knowledge, so the presented design comes to add emotional value to the content offered, either in the first contact or during the continuity of the study while maintaining the enthusiasm of the student the course.

A good education project should pay attention to all the details so that its material is coherent, complete and attractive for the students. This article discusses the research carried out concerning the influence of graphic design on the innovation of a core of business and social studies that offers several courses of specialization and improvement, free courses and consultancies in different disciplines within a university.

Considering the large areas of the Table of Areas of Knowledge / Assessment of CAPES [3], the studied project offers courses in Exact and Earth Sciences, Applied Social Sciences and Human Sciences. In addition, it welcomes students trainees of the same areas and of Linguistics, letters and arts. The clear multidisciplinarity of the core of studies proposes to arouse the esteem of varied audiences, and to ensure that these are achieved the design and publicity team works in order to bring individuality within the project unit, following the functions of graphic design that are to identify, inform and instruct, present and promote [4]. This article exemplifies the importance of the work of these teams and the methods used by them to assist the path of educational project towards excellence.

\section{Graphic Design in the Educational Background}

Design is present in our day-to-day life in many ways. There are many definitions for the term, which also takes into account the various aspects of the profession that allow professionals to act in multiple ways.

"Design has been ubiquitous since its social institutionalization in the 1950s. Since then, there is no doubt about the usefulness of design; he became the owner of his own discourse through economic policy, presence in the media, culture and advertising. "(Gert Selle apud BURDEK) [5] Nowadays it is common to see the word design being used to refer only to the stylization of something, but it is, moreover, the design and the elaboration of projects.

\subsection{Graphic Design}

Among the aspects of design we have the graphic, which is the set of activities aimed at the creation and production of visual communication objects [6], which uses visual language to convey a message. At first it was an expression that was directed to the creation of printed materials. With the advancement of technology the term began to cover the application in other means of visual communication. Both books, magazines, newspapers, websites, blogs, web pages, different sources of information and dissemination need to use visual language in the best way to reach their purposes. 
In the advertising medium it is important to observe the target audience so that it is reached effectively. The reading of graphic objects occurs in a unique way for each individual, but there are interpretations based on general concepts related to color, icons and arrangement of elements that similarly affect most people. From that point on, the creation of projects that use visual language should hold the majority interpretation to create content that is clear to readers, even if unconsciously. Soon the designer must design their artifacts considering the information to be transmitted and the feeling to be generated.

The final material must be consistent with the original idea, just as it needs to be understandable to those who want to achieve it, being objective and clear. The diagram uses the typographical hierarchy and the readability to highlight and / or emphasize certain words, expressions and texts. There must be a study before the choice of colors to be used, so that these are cohesive with the sensations that are intended to convey. The use of images must be in accordance with the set, adding the art without distracting the reader from the main scope. Those that are most important for understanding the subject must be legible and accompanied by captions when necessary. All the details of the composition of a graphic object must be analyzed and balanced according to the purpose, means of dissemination and the end user.

\subsection{Design and Education}

Authors like Jacques Delors [7] already indicated that education, much more than mere erudition, would become in the third millennium a strategically important element for the world. It should be pointed out that we understand education as a process that involves teaching, but it is not circumscribed, so that there is in the notion of education from which we started, much more than the mere memorization of content, there is the learning of models of sociability and strategies for seizing information that will come (being successful the planned educational process) to become knowledge.

By following this line of reasoning, we deduce that education must prepare the student to live in society, so that the student participates actively and is not only servile to it. Thus, it is the role of education to provide the knowledge necessary for the student to achieve his or her professional goals and perform his or her duties and rights before the same society (UNESCO, 1998) [7]. In this context, design can be used as a pedagogical tool, since the process to carry out a project requires creativity and promotes problem solving [8]. Thus, design allied to education can enable the student to develop new things and deal with eventual problems [9].

When it comes to teaching, it is common to associate this term with places like schools and universities, classrooms with pictures and projectors with a teacher on the way passing the subject to a class full of students. But today there are other ways of applying and gaining knowledge. The technological evolutionary process has brought alternatives into the halls and out as well. If educational institutions already make use of slide presentations, access to online and offline virtual data, nowadays distance education is much sought after as an educational facilitator. Classes that attend classes and lectures with teachers who are not actually present, distance learning courses through virtual platforms, video-lessons, online tutorials and / or self-taught learning sites, the options are multiple and the student has several opportunities. 
To keep up with advances, educational institutions need to adapt and try to offer the most varied options for their possible students. Existing competition due to many perspectives requires that educators are constantly adapting the ways they teach their classes.

The collaboration of design at this time comes in the preparation of the study material and in the promotion of it. The designer Gui Bonsiepe says that:

"The design can facilitate its reception and interpretation, allowing a more efficient action. [...] there is a fundamental difference between knowledge and action-oriented information: knowledge is more than information. Knowledge allows you to filter an informational value from a mass of data. Knowledge is a way of discovering the world: to recognize, to understand and to grasp. As opposed to information, whose importance is relevant to action, one can consider that knowledge is not always oriented to the execution of tasks." [10]

Visual communication thus contributes not only to the dissemination of institutions, projects and schools, but also helps in the best way to present its content.

The designer studies methodology in order to choose the best method to carry out a project. And for this he needs to be aware of various techniques and organize the information he needs to find solutions to theoretical and practical problems. In this way the designer's world view can contribute to teaching to develop more effective ways to help the student to qualify.

With the current education model and in view of the wide use of technology in different situations, the design can offer projects in order to facilitate and increase the level of understanding of the student in several areas.

\subsection{Socialization of Teaching}

The nucleus of university studies is hierarchically linked to the pro-rectory of extension. This manages academic projects with the purpose of applying their resources as knowledge, techniques and tools directed to meet market demand and institutional strategies. They stimulate the analysis and development of national and international extension activities aimed at improving business management and social development. They seek to integrate the university to society with scientific commitment beyond its physical facilities. In addition, they are another channel of interaction between private and public entities and government agencies.

Within the university, the core activity generates opportunities for the engagement of teachers and students from different areas in research and teaching projects. The transdisciplinarity of knowledge that occurs among its components enables a unique experience of how current companies around the world work, as well as being an additional motivator for the student body by creating opportunities for engagement in practical applications in the training phase. Interaction with other professionals with a more corporate or practical application of science also generates gains both for the university and for society.

To reach this result, they make available their skills to various social groups, with distinct intellectual interests and using means that facilitate access by them. These courses are taught in 
the university environment with teachers from different areas. But the core has throughout all its educational works converging so that the courses are also formatted for the environments of Distance Learning, in order to meet two objectives: 1 - To reach any individual who has access to the Internet; 2 - Perpetuate the knowledge of professionals and teachers, since the courses when prepared and placed in the virtual environment, can at any moment be visualized.

The aim of this study project is not only to transmit knowledge purely but also to open up learning opportunities for different audiences in different environments, through different means and methods of communication. The notion of learning environment is very expensive, since much more than linearly directing content from a transmitting pole to a receiving pole, there is the facilitation of learning through the provision of choices made by the learner through the use of Information and Communication Technologies ( TICs) developed by the designer with the purpose of involving the learner from several integrated information channels (texts, videos, directed exercises and animations, for example).

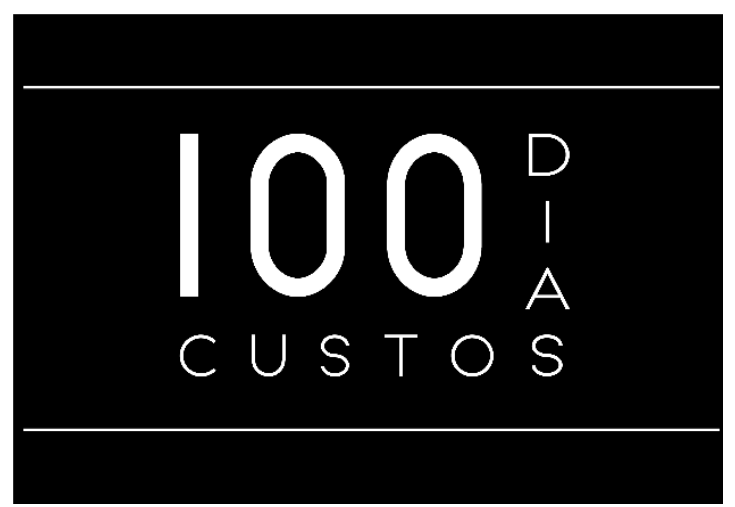

Figure 1: Poster for divugation of temporary and free distance extension courses.

As a result of this ongoing project (taking into account the theoretical perspective that there is nothing in science that is ready and finished, and there is always the possibility of improvement from what has been produced up to now), two (although others may be mentioned): a) the expanded scope due to the possibility of using EAD in places far from the headquarters where the educational project is being developed. The internet allows the virtual learning environment to be accessed almost anywhere on the globe, which is a significant strategic advantage; b) the knowledge produced ceases to depend on material bases subject to bad weather or accidents (for example: library fires). Using the servers and the data cloud enables the durability and refinement of the materials to be simpler and less costly.

\section{Results and Discussions}

\subsection{The Use of Visual Communication in the Innovation of Teaching}

The object of study for this article was a teaching project that acts as a nucleus of support to the entities and people of the academic community in transforming ideas into extension actions. In it are offered face-to-face courses and distance learning in several areas of knowledge. You can access extension, specialization, and enhancement certificates. The faculty is formed by 
professionals who are dedicated to adapt their teaching methods to the different means of access that students can take to the courses.

For all these possibilities to be realized, the project has teams of design, audiovisual, computing and advertising, formed by graduates and university graduates who help teachers and align all the material in their different platforms.

\subsection{Role of the Designer in the Academic World}

When studying various methods of design, the designer has varied views on a particular subject, this differentiates him from other professionals, since he does not have a predetermined form of thought. It should be pointed out that in the case of Distance Education (EAD), the designer performs more than one teaching action, contributing to the formation of habits, attitudes and study skills that greatly enrich the learning of the students connected to the courses which have professionals of this type. This profile can help the academic environment to better understand the user and to know the best didactic to approach certain content. With this preliminary study, it is possible to uncomplicate subjects and bring knowledge to the student, as the designer Gui Bonsiepe proposes when talking about the role of the profession:

"Designers could intervene exactly at this point because they dominate - or should dominate - the means to reduce cognitive complexity and contribute to presenting information in a useful way, developing an appropriate interface between the information and the user / reader. This new type of design is known by different denominations, such as information architecture or knowledge engineering. I prefer the term cognitive design, that is, to facilitate the assimilation of information. "[10].

Based on this citation, the design team of a core of corporate and social studies at a university, not only assumes the function of making and disseminating a product, but rather informing / guiding the user. Thus, it covers from the term of cognitive design to that of information, since in selecting and organizing information it presents them more clearly and with that, it shapes them for a given user [11].

Cognitive and informational design are present in all activities related to the teaching that the core offers. Initially, the designers worked with the creation of the visual identity of each study area in order to be easily identified by the user. In this process of creation, the team received a briefing of the content of the material developed by professionals of the area, then the concepts were defined after being extensively studied from keywords, until reaching the point where it becomes easy to associate the areas. With the defined concepts, the meanings of the colors were studied to see if they were compatible with the desired message and tests were carried out in order to choose a color palette. In the color palette, harmony was sought at the junction by means of overlap analysis and use tests for both virtual and printed media, in order to be used together as a typographic family for contrast, not to disturb reading and not to weigh the visual composition and yet be recognized as part of a whole if used separately. 


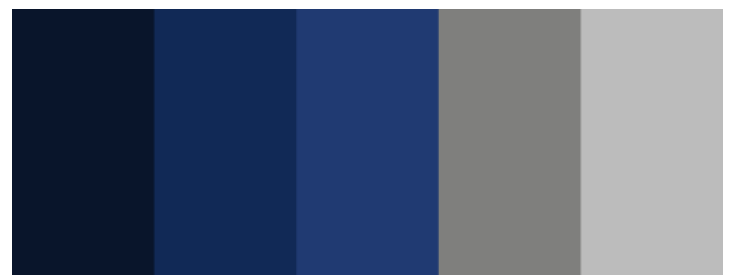

Figure 2: Color palette for project visual identity

With the definition of the color palette was developed the symbol that is the main visual code and based on it the entire line of graphic resources was diagrammed. The development of the symbol took about a month to complete, as the team members developed six alternatives with the palette of colors and fonts. After the generation of the alternatives, a meeting was held in which most of the support staff analyzed them and saw if something could be added and / or changed. Then, with due changes, tests were made of: shadows, transparency, perspective. It was decided that the symbol would have two versions: tinted colors and with effect of three dimensions.

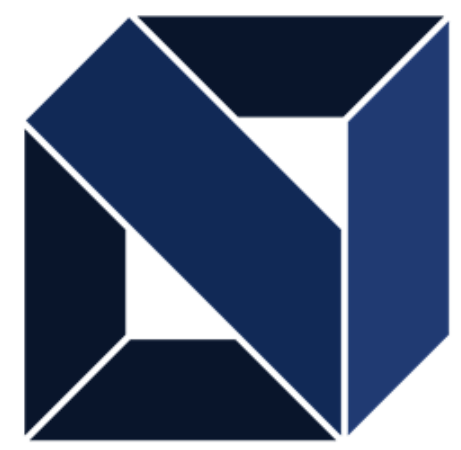

Figure 3: Symbol generated

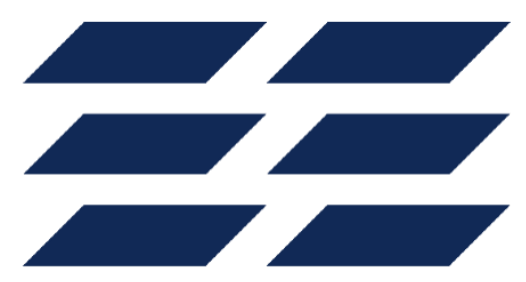

Figure 4: Shapes generated by architeture inspiration

Subsequently, the team created a typography that corresponded to the concept because the purpose was that only the use of it already referred to the architecture of the university in which the entity is located. The goal was achieved by using the law of closing the Gestalt principle, as it used perspective to create geometric shapes of acute angles and the three-dimensional effect from the color palette.

With the symbol and the typography were created visual patterns in which the logo could be used. The manual of the brand was carried out in days, since the team already knew how to identify: what colors to use for each letter of the typography and the symbol, the best way of positioning 
the set and how they would be used separately. They created a version for dark and light background. It was decided that both could be used separately, however, if together the symbol came first the left and the typography, with the same height, the right.

With the visual identity ready, it was analyzed by professionals of the audiovisual and information technology team present in the social project. As it was approved, the printed and virtual material was diagrammed respecting the brand manual and using the silhouette of the symbol to dynamize the reading and draw the attention of the target public without harming the important information of the material.

When working with the printed material, they first decided the dimension that was printed on the graph and then what visual components that differentiate it from the other institutions and attract the target audience. In view of the purpose of informing about subjects offered by the study project the printed material is usually the gateway of new students to the nucleus, since it contains clear and necessary information for the knowledge of the subject in order to carry out the inscription in the subject. If the student is more interested, the printed material directs him to the interactive site of the project that has more detailed information about the subjects and was done with the intention of providing a simple navigation, since each part of the site is easily accessible to the user.

The project designers apply visual communication to attract and inform objectively what is needed for the user to become interested in and enroll in the educational project. Upon your entry you receive the didactic materials that were planned with visual and sound components to make learning a simple experience without many obstacles to the assimilation of information.

\subsection{Technology and Design Allied to Teaching}

Thanks to technological evolution, people today have access to various types of information. However, most are not filtered in order to teach something and many users end up consuming unnecessary information that only overwhelms them. Therefore, designers use the information design strand to format the material that is intended for teaching.

"Information design takes place in analog and digital information environments that seek to visually present certain points as goals, taking into account their intended audience, processes and results. The organization of data and information is a process that seeks to recognize the meaning of content to refine and reduce an abundance of data in meaningful and usable information." [12] The team makes intentional communication in all means of information dissemination. Especially those destined to distance education, since the message to be interpreted needs to be planned and structured so that the student understands and stays focused on the subject.

In social networks the team plans the publications at least a week in advance, to ensure greater interactivity with the public that already follows the platforms and reach more people. For this, the arts destined to these ends are made with specific dimensions and for each social media was defined a model of language, the arts contains key words that even without the legends that the social networks offer can be shared and understood individually. Thus, each social media has a different language, but pass the same message. In this way, depending on the situation, each platform can meet different needs. 

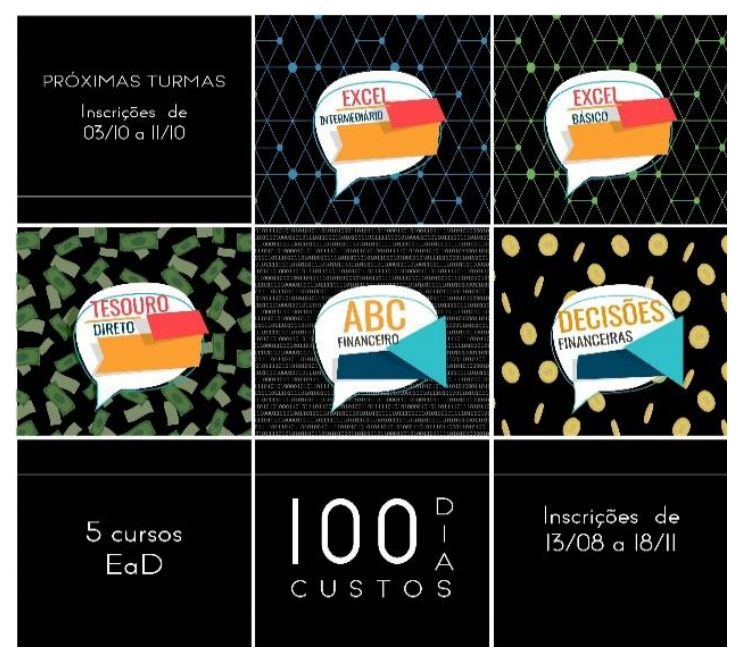

Figure 5: Set of images for for visual communication in social media

With greater interactivity the student enjoys more dynamism in learning, since all the platforms were developed in order to offer the best experience for him. It is possible to access the teaching material through a cell, tablet or computer screen. No matter the medium, the student has the best material available, because it was designed for all dimensions and designed so that it does not make the reading tiresome, nor that the colors used bring conflict with the information inserted.

Thus, technology is a tool that the designers of the support nucleus use widely to guarantee its main objective: to offer information and to add knowledge. By this means the design expands the target audience and adds value to those who are in search of professional improvement. However, graphic design alone is not enough to cause such an effect, so computer and audiovisual teams actively participate to provide effective knowledge. Teams that have been together for more than a year have improved the efficiency of knowledge transmission across all project information platforms through UI Design that addresses user interaction with the UX interface and UX that treats the experience.

"But, after all, what exactly is an interface? In its simplest sense, the word refers to softwares that form the interaction between user and computer. The interface acts as a kind of translator, mediating between the two parts, making one sensitive to the other. In other words, the relationship governed by the interface is a semantic relation, characterized by meaning and expression, not by physical force." [13]

\section{Conclusions and Recommendations}

In the current world scenario the use of technology in several areas makes it possible to introduce this as a didactic tool. However, the present article differs in showing the importance of introducing graphic design as a support for teaching, in this way, the traditional method of education is redesigned and improved to increase the knowledge of others, causing social and economic. The social impact is directly felt by the people who pass through the various courses that have already been offered by the nucleus. 
The association between ICT professionals and graphic designers has much to contribute towards producing meaningful learning in terms of instructional materials and courses, as well as the advancement of knowledge in Education and related areas, which through the interdisciplinary work process involved in the creation of virtual learning environments that support each of the courses developed.

In corroborating with new forms of learning, the graphic designer maintains an intimate relation with education, contributing from his expertise so that mere information becomes a learning environment capable of taking the subjects immersed in it to new levels of knowledge regarding the matters.

Because there is still a long way to go, the current direction of the nucleus sees in transdisciplinarity a way to overcome new challenges that the project may face. Always using the technological advances in your favor in the adaptability and progress of the services provided.

\section{References}

[1] Tatiana Tabak, Possible Dialogues between Design and Education: contributions to the formation of reflective teachers, https://www.maxwell.vrac.puc-rio.br/16636/16636.PDF.

[2] Paz e Terra. 1959. Education: The practice of freedom. Rio de Janeiro. ISBN: 9782868870322.

[3] CAPES, Table of Areas of Knowledge / Evaluation, http://www.capes.gov.br/avaliacao/instrumentos-de-apoio/tabela-de-areas-do-conhecimentoavaliacao.

[4] WMF. 2010. Graphic Design: A concise story. (2nd. ed.). São Paulo. ISBN: 978-85-7827-345-3.

[5] Edgard Blucher. 2006. Design: History, theory and practice of product design. São Paulo. ISBN: 8521203756.

[6] Rafael Cardoso, The graphic design and its history, https://docente.ifrn.edu.br/

[7] Cortez. 2001. Learning: The Treasure Within. São Paulo. ISBN: 85-249-0673-1.

[8] Edgard Blucher. 2001. Industrial design: basis for configuration of industrial products. São Paulo. ISBN: 978-85-212-0288-2.

[9] Birkhäuser. 2007. Designerly ways of knowing. Basel. ISBN: 3-7643-8484-0.

[10] Edgard Blucher. 2011. Design, culture and society. São Paulo. ISBN: 978-85-212-0532-6.

[11] Thames \& Hudson. 1998. Information graphics: innovative solutions in contemporary design. New York. ISBN: 0500018723.

[12] João Oliveira, Maria Jorente, Information design and information science: a possible approach, http://www.brapci.inf.br/index.php/article/download/43876.

[13] Zahar. 2001. Interface culture: how the computer transforms our way to

\footnotetext{
*Corresponding author.

E-mail address: marcosanfins@ gmail.com/ morganamasuko@ id.uff.br/ paulafigueiredo@id.uff.br/pablobispo@id.uff.br
} 